\title{
Strategic Planning as a Catalyst for Change in the 1990s
}

\section{Meredith Butler and Hiram Davis}

\begin{abstract}
If research libraries are to have desirable futures, they will have to create them. Strategic planning can assist library administrators in assessing their environments, identifying alternative futures, and creating change in their organizations. It can also serve as a vehicle to empower library staff and to increase the library's external visibility. Two recently appointed research library directors of ARL libraries discuss the importance of strategic planning and offer several examples of ways to engage library staff, university faculty, administrators, and students in the planning process. The expected outcomes of such a group process will be library plans which are relevant to the institution, which relate decisions to resources and opportunities, and which increase visibility for the library on campus and in the community.
\end{abstract}

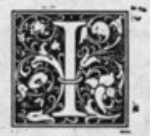

n A Raisin in the Sun, Lorraine Hansberry's character, Beneatha, presents a disturbing image of the human condition: "Don't you see there isn't any real progress, Asagai, there is only one large circle that we march in, around and around, each of us with our own little picture-in front of us-our own little mirage that we think is the future."1 Some would argue that Beneatha's pessimistic judgment about the inability of humans to see "the big picture" and the circular nature of human progress accurately describes the condition of today's institutions of higher education. Erosion of public confidence in higher education and continuing dramatic reductions in fiscal support severely limit opportunities for educational renewal, growth, and change at this critical juncture in our nation's industrial and technological development. Nowhere are these limited opportunities more immediately felt than in the nation's research libraries because thêy are, by definition, concerned with "the big picture" and because their progress is most immediately affected by fiscal conditions. Today's academic librarians may not be marching around in a circle, but we surely feel that we are running on a treadmill. As we librarians struggle mightily to maintain forward momentum, we are continuously pressed back by the relentless pressures exerting force in the opposing direction.

For those of us leading academic libraries in the 1990s, the forces pressing us back include budgetary reductions, rapidly rising costs, reduced staffing, increasing complexity, escalating demands, and a national temper that has lost patience with higher education - some might say, a national temper that has lost faith in the value of higher education. Pushing us forward is the vision of a technologically enhanced future which will allow fundamentally different approaches to teaching and learning and will enrich the research enterprise. As we run on our

Meredith Butler is Dean and Director of Libraries at the University at Albany, State University of New York, Albany, New York 12222, and Hiram Davis is Director of Libraries at Michigan State University, East Lansing, Michigan 48824. 
treadmill, trying to cope with these opposing pressures, realities, and visions, we are turning increasingly to strategic planning as a powerful management tool to help us analyze, reconcile, and integrate disparate and often conflicting individual images of the future into a coherent, compelling, and shared vision toward which we can progress with optimism, vigor, and conviction.

The accelerating rate of change and the increasing complexity of our professional environments in the past ten years make it no accident that strategic planning came into its own in academic libraries and professional associations during this same period. The literature on strategic planning in the business world is extensive and rich. The literature on strategic planning as it applies to higher education and, more particularly, to academic libraries has been slower to emerge but has been developing rapidly in the past five years. In the late 1970s and early 1980s, authors like Robert Cope, Philip Kotler and Patrick Murphy, George Keller, and Richard Jonsen took the basics of strategic planning, as defined in a standard work like George Steiner's Strategic Planning: What Every Manager Must Know, and applied them to higher education. ${ }^{2}$ These articles defined the characteristics of strategic planning, discussed how it could be implemented, related it to organizational environment and the allocation of resources, and laid the foundation for strategic planning in higher education. Building on this foundation, articles by Charles McClure, James Healey, and Richard Lenz et al. began to focus on the importance of planning for academic libraries. ${ }^{3}$ These authors defined strategic planning and compared it to other types of planning. They described each stage of the planning process, provided strategies for implementation, and advised on the development of effective group processes and the strategic thinking skills of library managers.

By mid-decade, articles on strategic planning and its application to library management were growing in number and scope. Elizabeth Wood, in a forward-looking article, showed how the basic principles of marketing and strategic market planning might be applied to libraries as a response to the issue of library survival. ${ }^{4}$ In 1984, Donald Riggs produced the first handbook devoted exclusively to strategic planning in libraries to "provide general and procedural information on how to go about adopting strategic planning into the library management construct." ${ }^{15}$ In 1985, Barbara Moran provided a brief overview of strategic planning and its application in libraries and made reference to an ARL SPEC Kit survey of thirty members' planning efforts which evaluated these planning documents as primarily "descriptive" with "some strategic features."

\section{If librarians and their libraries are} to benefit fully from strategic planning, they must first understand and confront the environment in which they work and in which libraries exist.

A 1987 study paper by Mark Meredith et al. provided guidance on the ways in which strategic planning differed from other types of planning and reported results of a survey of one hundred higher education institutions that showed a "smaller proportion of institutions than previously indicated appear to be actually conducting strategic planning." 7 Peter F. Drucker, whose 1974 book Management: Tasks, Responsibilities, Practices, served as a primary textbook for many library administrators interested in planning, emphasized the necessary connection between strategic planning, innovation, and entrepreneurshipin his 1985 publication onentrepreneurs and creativity. ${ }^{8}$ Robert A. Hayes stressed the need for strategic plans to focus on quality rather than quantity, to focus on a set of activities and goals to be pursued rather than things to be counted. ${ }^{9}$ Robert C. Shirley provided helpful guidance for the novice planner in the form of case studies. ${ }^{10}$

Ida Vincent raised questions about the applicability or the "fit" of the strategic planning model to libraries and offered six case studies to illustrate her conten- 
tion that libraries may lack the requisite autonomy, power, and funding stability that the strategic planning process requires. Vincent concluded that "the most valuable outcome of a strategic planning exercise is not the planning documents which result, or even the process of examination and re-examination of objectives and activities, but rather the attitudes and habits of mind which the exercise requires and can help to develop." She called this "a planning mentality."1 In a 1987 article, Riggs stressed the connection between strategic planning and entrepreneurship in library management, the need to plan for calculated risks and to develop contingencies. Riggs assigned the library director an essential role in strategic planning in both providing leadership to the planning effort and creating and fostering "a management climate that encourages innovation and change." ${ }^{12}$ In a later article, Riggs broadened his focus on strategic planning and reminded library leaders to factor in the benefits of networks in their institutional planning. ${ }^{13} \mathrm{~A} 1990$ article by Rick B. Forsman underscored the importance of organizational and employee values in a strategic plan. "By acknowledging values and making an effort to blend them into the plan itself, the chances of successful and timely completion are increased." 14

A recent and excellent addition to the literature on strategic planning in higher education is the special issue of the Journal of Library Administration which contains a series of articles on strategic planning in academic institutions and their libraries..$^{15}$ Articles discuss aspects of strategic planning in institutions as various as the University of Iowa, Wayne State University, the University of Cincinnati, and The Pennsylvania State University. Of considerable interest in this collection are the diverse views on planning as seen through the eyes of college and university presidents, campus planners, and librarians. The articles by James Rosser and James Penrod and by Gordon Eaton and Jean Adams illustrate the importance of presidential leadership in institutional planning, while
Nancy L. Eaton discusses how the library might be integrated into an ongoing institutional planning process. Beth Shapiro describes an institution with a well-developed planning process that most often overlooked the library or included only top library administration in key discussions. As a result, the institution's collective vision statement was uninformed by the knowledgeand wise counsel librarians could have contributed, and

\section{Strategic planning processes create opportunities for staff at all levels of the organization to inform themselves about the organization and its environment and empowers them to work creatively.}

library staff were unprepared to make difficult choices between competing programmatic priorities or decisions about budgetary reallocations. Nancy Cline and Salvatore Meringolo trace the evolutionary planning process at Penn State and discuss the impact of planning on the organization in an institution where planning is closely tied to resource allocation. In short, this special issue of The Journal of Library Administration is an excellent point of departure for any researcher exploring the diversity of approaches to strategic planning in higher education.

Equally useful is the recent article by Bonnie Gratch and Elizabeth Wood which not only details the planning process undertaken by the library at Bowling Green State University but also provides information about the implementation of the plan, its effects on library operations, and a candid assessment of the plan's impact in its first year with suggestions for revision and improvements. ${ }^{16} \mathrm{~A}$ recent article by Brice G. Hobrock reminds us that strategic planning, however, is not without serious consequences. Hobrock underscores the importance of strategic planning for organizations where resources are declining and reminds readers that all choices are choices among alternatives competing for resources and that the effect of 
strategic choices is to eliminate or modify existing programs and reallocate resources to new programs seen as more facilitating of future success. ${ }^{17}$

These and other examples in the literature attest that, in 1991, strategic planning has come into its own in institutions of higher education and their academic libraries. While the literature on strategic planning is growing and becoming richer in both content and variety of approach and example, many issues have yet to be examined and many areas of research have still to be explored.

Unlike many of the articles discussed above, this article moves away from the usual focus on what strategic planning is and how an academic library does strategic planning. It explores why strategic planning is important and why it is particularly important to engage in strategic planning in periods of austerity or rapid change. The authors will discuss the benefits to the organization and the library staff to be derived from the planning process, and equally, if not more importantly, how strategic planning may influence some of the political realities faced by most academic libraries and their directors.

\section{THE CULTURE OF THE RESEARCH INSTITUTION AND ITS LIBRARY}

As is evident from the literature, higher education has adopted strategic planning with enthusiasm and, in the past decade, many colleges and universities have used the processes of strategic planning to help chart their future directions and position themselves to best advantage. Many academic libraries have also engaged in formal strategic planning processes, often with the expert assistance of staff from the Association of Research Libraries' Office of Management Services or other knowledgeable library professionals. Examples of ARL libraries which have completed strategic planning processes recently and have made their plans widely available include the libraries of the Massachusetts Institute of Technology, Rutgers, Brown University, Wayne State, the University of Tennessee, the University at Albany, State University of New York, and Michigan State University.
While many librarians are attempting to manage strategically and are trying to position their libraries to function more strategically, what does it all mean? Why is strategic planning important, and what benefits may be derived from what is, after all, a difficult and enormously time-consuming process? The authors hope to answer these questions in the second part of this article and to illustrate their answers with examples from their own experiences of strategic planning.

If librarians and their libraries are to benefit fully from strategic planning, they must first understand and confront the environment in which they work and in which libraries exist. Perhaps the greatest strength of strategic planning is that it provides a process whereby library administration and staff can analyze their environment and relate the results of their analysis to organizational goals, objectives, and future plans.

It has been argued that, organizationally, academic institutions are among the most complex structures in modern society. ${ }^{18}$ In his 1988 book, A Free and Ordered Space, A. Bartlett Giamatti asserts: "American institutions in general and those for higher education in particular have been coping, but they have not adapted to changing times, and they are no longer perceived as leading." ${ }^{19} \mathrm{Gia}-$ matti makes the distinction between being competently managed and being led. He sees leadership as an essentially moral act in which the leader asserts a vision of the future and has the intellectual energy to persuade others of the validity of that vision. ${ }^{20}$ When leadership and common agreement on a desired vision of the future are lacking in higher education, the void is most immediately felt in the academic library. The academic institution provides the setting, impetus, and model for the structural organization of the library, and the latter must conduct its functions with respect to and within the culture of the larger academic environment. The academic library, similar to other organizations, is dependent on its environment for its survival, its resources, and the definition of its mission and objectives. 
At the same time, the parent institutions present academic libraries with perhaps their greatest problems and challenges. For example, Michael Cohen and James March have characterized the academic environment as an "organized anarchy," and point out that such institutions have multidimensional and problematic goals, inadequate information technology, fluid participation, and turbulent environments. ${ }^{21}$ Other significant characteristics of academic environments can include outdated hierarchical structures, organizational fragmentation, sexism, racism, significantdemographic shifts in the composition of student populations, competitiveness, high personnel costs and labor intensive practices, and economic stringencies. Thus, within the academic culture, academic libraries occupy, according to Keller, special "hazardous zones" - marked by unprecedented changes and adjustments, growing expectations, turbulent environments, increasing austerity, and uncertainty about the future. ${ }^{2}$

The political reality for most academic libraries is that while there is a great deal of institutional rhetoric espousing the centrality of libraries to teaching, research, and learning, libraries are often excluded from policy decisions that have major impact on their services, funding, or staff. Ample evidence from experience and from the library literature indicate that research libraries, their directors, and their librarians often suffer from benign neglect, a lack of contact with upper-level administrators, and a lack of access to the upper levels of the academic power structure. ${ }^{23}$ University administrators may think well of the library, but they don't think about it often, and they frequently overlook it when developing plans and determining strategies for the future. The challenge then is how to thrive in this kind of environment.

\section{THE IMPORTANCE OF STRATEGIC PLANNING}

Active engagement in the institution's planning and policy-setting processes has particular importance for today's academic libraries. Strategic planning provides library directors and their staffs with an excellent process for addressing policy vacuums and for overcoming some political limitations and organizational barriers. It is a process that shifts the library, both organizationally and functionally, from a reactive mode of coping with the present to a proactive mode of envisioning and moving toward a clearly defined and desired future. It requires both staff and administrators to think strategically about the future and to choose from among many possible alternatives and competing pressures only those strategic choices that are consonant with institutional and external opportunities, and only those choices that maximize resources and move the organization most efficiently toward its goals and toward a viable future.

Strategic planning assists the library in being responsive to constituent and organizational needs in order to develop strategies sufficiently flexible to take advantage of today's unprecedented confusion of opportunities. In fact, successful strategic planning can help libraries develop and maintain a strategic fit among resources, organizational needs, and the changing opportunities in their environments.

A successful strategic planning process also requires the active participation of many library staff and faculty, staff, and student constituents. Healey and others note the value of using group process as a means of involving staff in planning and decision making and the benefits derived for the organization. ${ }^{24}$ Academic libraries are complex organizations with interlocking and interdependent operations. They must rely on shared expertise and group problem solving if they are to operate with increased effectiveness and achieve their goals. Strategic planning processes create opportunities for staff at all levels of the organization to inform themselves about the organization and its environment and such processes empower them to work creatively and cooperatively to choose effective strategies and reach common agreement about goals.

Strategic planning also provides wonderful public relations opportunities and can serve as the vehicle for moving the library more dynamically into the university environment. For example, it can set 
the stage for engaging university officials, faculty, and other major stakeholders in discussions about institutional policies and priorities for library resources and services. Active engagement of campus faculty and administrators in discussions about library plans and services is especially important in times of fiscal austerity and in environments characterized by fierce competition for limited resources. Such discussions can lead to a new consensus or reaffirmation of the significance of the library's role within the academic environment. This is especially important as academic libraries move to a new paradigm of electronic storage and access in order to remain viable information systems in the twenty-first century.

Perhaps one of the most important benefits of strategic planning is the opportunity to do environmental analysis or scanning. J. William Pfeiffer identified five distinct and overlapping environments which must be taken into account: the macro environment, the industry environment, the competitive environment, the customer environment, and the organization's internal environment. ${ }^{25}$ Organizational survival is directly tied to the need to be aware of what is happening in all these environments. Given the wide range of existing campus and library issues (e.g., changing demographics, funding accountability, curriculum revisions, internationalism, diversity, aging physical plants and equipment, emerging information technologies, to mention a few), libraries and library administrators need to be especially aware of and responsive to their organizational environments. They also need to assist other academic colleagues to understand the very complex and rapid changes taking place in the library and information industry. Indepth examination of each of these environments and related factors can provide substantial information and data to position the library more strategically within the larger academic environment.

Environmental scanning can be an enormously enriching process. First, it serves as a reality check and helps to underscore institutional goals and objec- tives and, more importantly, institutional priorities. Careful environmental analysis answers such questions as: What academic programs are well supported? What programs are exempted from budget reductions? What new facilities are being built or remodeled? What is the nature of key institutional appointments and promotions at faculty and administrative levels? Environmental scanning also highlights emerging trends and issues and can serve to identify opportunities, competitors, and potential partners. Finally, environmental scanning provides a mechanism for relating library plans and goals to those of the institution. However, a note of caution is in order. Environmental scanning is not a one-time function. It should become an integral part of the way in which the library conducts its business and must be done on a cyclical basis to be an effective part of a strategic planning process.

\section{LIBRARY EMPOWERMENT}

Strategic planning has been particularly successful and empowering for two academic libraries that have recently completed the process, the libraries of Michigan State University (MSU) and the libraries of the University at Albany, State University of New York (SUNY). When Michigan State University Libraries launched its year-long strategic planning initiative, the process was structured to change (or perhaps more realistically, to influence) the external and internal culture in which the MSU Libraries operated. The intent was to implement change strategies that would benefit the university, the faculty, the users, and the library. The goal was to integrate the library into the university's ongoing strategic planning process. The library deliberately involved others in making decisions about the library's future. In so doing, the library staff gained a better understanding of its external environment; at the same time, others gained better insight into the library's internal environment. The process resulted in enhanced visibility for the library and produced substantial information and data for better positioning the library within the university. MSU 
Libraries' strategic planning served as an excellent reality check. First, it helped staff learn about institutional priorities. Second, it highlighted emerging trends and issues and assisted staff in recognizing opportunities, assessing the strength of competitors, and identifying potential partners. Third, it provided a mechanism for identifying and clarifying library goals and plans and relating those goals and plans to those of the institution.

Strategic planning at the University at Albany, SUNY, proved to be similarly empowering. Although the university and the university library had engaged for many years in a well-developed campuswide planning process in which every department, school, and college prepared a five-year plan with annual updates, the planning was a top-down administrative process. Plans were not shared among schools and colleges, each unit planned independently with little outside consultation or coordination, and littleopportunity existed for staff and faculty involvement. Library planning was an internally focused process done with minimal consultation with faculty, students, or staff, and little correlation between planning priorities and budget allocations. Since strategic planning requires a thorough examination and analysis of challenges and opportunities posed by the external environment, the lack of a comprehensive environmental scan was a serious weakness of these plans.

Albany's fifteen-month strategic planning process was designed to address these weaknesses: to involve library staff, campus faculty, and administrators; to do a thorough environmental analysis and internal assessment; to set goals and priorities and relate them to the budget; to inform the library's public of plans and priorities; to increase the visibility of the library, its staff, and services within the university and the community; and to foster a more forward-looking environment in which change was seen as necessary and positive.

\section{STRATEGIC EXECUTION}

Much of the benefit of strategic planning is derived from the careful execution of a well-developed and strategically sound process. Robert $\mathrm{H}$. Waterman, Jr., underscored this point in his article, "The Seven Elements of Strategic Fit," when he asserted that "a good strategy is not synonymous with a doable one. Nor is a doable strategy synonymous with a good one. The challenge is to find a good doable strategy." ${ }^{26}$ To assist his readers in determining whether a particular strategy is doable, Waterman offered a planning framework which he called the 7S Framework: strategy, structure, systems, style, staff, skills, and shared values (see appendix A). Waterman believed that all of these interdependent factors must be taken into consideration in strategic planning if the process is to be successful. Given the wide range of existing campus challenges facing academic libraries, librarians are confronted with the necessity of making major changes in their organization's culture, their organization's structure, and, perhaps, in its shared values. They require not only new strategies, but doable ones. Illustrated below are some of the strategies used in the strategic planning processes of both the MSU Libraries and the SUNY Albany libraries which proved to be both doable and successful. Both libraries took the seven elements of strategic fit into consideration in their planning processes.

Albany built its strategic planning process around a series of events that served as vehicles to involve many people in the process. These events also served to focus and strengthen the process and to foster group solidarity. The first event was a catered "working dinner" hosted by members of the strategic planning committee and held in an elegant setting to acknowledge both the value placed on everyone's commitment of time and energy and the significance of the undertaking. The university's vice presidents and the director of university planning were invited to discuss environmental trends in higher education and their plans and goals for the institution. The evening was very interactive. Members of the strategic planning committee read campus planning documents prior to the 
event and were prepared to ask questions, raise issues, and integrate library concerns into broader campus planning. This dinner was followed by a series of scheduled individual and small-group interviews with university deans, directors, and leading campus faculty as committee members gathered data for the environmental scan and used each meeting to highlight library issues and plans. In many cases, these meetings were the first opportunity faculty and librarians had ever taken to engage in substantive conversation about faculty needs and interests and library services and plans. Another event, a day-long seminar on strategic planning cotaught by the director of libraries and the director of university planning, brought all committee members up to speed on the content and process of strategic planning and provided them with a common base of information and a common opportunity for problem solving. Involving the director of university planning so actively in the library's planning process served several important goals, not the least of which was to increase library visibility since the incumbent in this position reported directly to the university president. Other goals realized by the experience included the opportunity for the director of libraries to work closely with the director of university planning on library planning and to exchange information about trends in higher education and the external and internal environments and for the library staff to be seen by the director of university planning as knowledgeable about trends and issues in information management and as engaged in the academic life of the institution.

Much of the work of Albany's strategic planning was done in small-group sessions. Full committee meetings were reserved for generating and discussing ideas, clarifying goals, planning the ongoing process, and for solving problems and building consensus. A special working retreat took place as each stage of the planning process drew to its conclusion to allow members to focus on content without distractions. Time for social fun and group bonding was always built into these retreats. Retreats were also planned to allow for full library staff participation at critical stages in the process and before draft documents were issued in their finished form. Not only did an excellent planning document emerge from this interactive process, but, more important, an esprit de corps developed in a variety of settings and especially among members of the strategic planning committee and its subcommittees. Through the strategic planning process, it became clear to everyone that although the library had a traditional hierarchical organization, the organization actually functioned on horizontal planes in which complex problems were analyzed and resolved by teams of experts from various levels of the organization. The entire strategic planning process used this group process approach to examine both the external and internal environments, to determine priorities, to solve problems, and to set directions. The authors believe that a planning approach which reduces the influence of hierarchy and emphasizes teamwork, shared expertise, and group problem solving is not only a doable, but a necessary strategy if libraries are to be successful in the fast changing and complex environment of higher education.

Similarly, Michigan State University Libraries' strategic planning process emphasized doable strategies. The first was to integrate the library more directly into the university's ongoing planning, and the second was aimed at reassessing, redefining, and reshaping the library program. The former was facilitated in part when the university's provost wrote articles that appeared in several campuswide publications outlining the nature of the library's strategic planning initiative and underscoring its importance to the university's programmatic planning efforts. In addition, letters inviting members of the library staff to serve on the library planning team came from the provost, who also sent letters to members of the strategic planning advisory committee which had representation from all major academic units. To ensure broad campus understanding and 
involvement in the process, a strategic planning newsletter, Visions of the Future MSU Libraries Strategic Planning Process, was mailed to all members of the campus community at key intervals. Finally, the strategic planning team identified a number of major stakeholders, i.e., individuals and groups that have an interest in the library's future, including university officials, faculty, deans, students, alumni, donors, and major campus departments. Stakeholder luncheons were held to provide the opportunity for substantive dialogue about university plans. The central focus of these discussions was on areas that required change, attention, and improvement, either within the uni-

\section{A planning approach which reduces the influence of hierarchy and emphasizes teamwork, shared expertise, and group problemsolving is not only a doable, but a necessary strategy if libraries are to be successful in the fast changing and complex environment of higher education.}

versity or library, to strengthen the library's future role and performance. As with the experience at Albany, these meetings at MSU were often the first opportunity for library staff to engage in substantive conversations with university administrators and faculty, to discuss needs and interests, to highlight library issues and plans, and to integrate these into universitywide planning.

MSU's strategic planning process was organized into three phases. The initial phase-strategy development-identified and clarified current and future issues and elaborated areas of concern in shaping the library's future. The second phase-information gathering-involved an in-depth analysis of the issues emerging from phase $\mathrm{I}$, the identification of major themes, and the development of recommendations based on subgroup analysis. The third phase-strategic implementation/integration-will guide the MSU Libraries through the transition from their current orientation to the academic library of the twenty-first century. As noted in the earlier discussion of Waterman's strategic fit, this third phase is actually the beginning of the MSU Libraries' strategic planning. While the library faces many challenges, MSU's staff has gained a sense of self-renewal because strategic planning has provided them with a process to identify and examine opportunities, assess risks, develop flexible strategies, and create their desired future.

\section{STRATEGIC FIT IN THE MSU AND SUNY ALBANY LIBRARIES}

By focusing sharply on all of Waterman's 7S framework, both libraries have been able to test the effectiveness of their strategic planning processes and to identify areas of incongruence between strategic aspirations and organizational realities. By focusing on doable strategies, both libraries improved their operational effectiveness, increased their visibility, and repositioned themselves within their universities. Through environmental scanning and internal assessment they discovered a number of changes that were needed to achieve strategic goals and developed plans to make those changes. Both libraries had to develop an organizational structure that was more horizontal and more client-centered. Both libraries have encouraged a management style that empowers staff to engage in group problem solving and decision making and encourages group solidarity. Both libraries are now more focussed on the external environment and work actively and opportunistically in the external environment to develop strategic alliances and promote services. Both libraries have gained immeasurably from increased staff understanding and support for library goals and objectives, for revised mission statements, and for new shared values and vision statements. To ensure that library staff function in their rapidly changing information environment, both libraries increased the emphasis on and support for staff training and development of skills. The libraries of both the Michigan State University and the University at Albany, SUNY have 
used strategic planning effectively to identify opportunities, assess risks, define goals, develop strategies to accomplish these goals, influence political realities and change academic cultures. They have been able to sustain their planning efforts and develop doable strategies that work. They are achieving organizational success within as well as outside their libraries and have created more positive environments in which change can be seen as an opportunity for growth and development and in which staff are empowered to take on new challenges.

\section{REFERENCES AND NOTES}

1. Lorraine Hansberry, A Raisin in the Sun (New York: Signet/NAL, 1988), p.134.

2. Robert G. Cope, Strategic Policy Planning: A Guide for College and University Administrators (Littleton, Colo.: Ireland Educational Corporation, 1978); Philip Kotler and Patrick E. Murphy, "Strategic Planning for Higher Education," Journal of Higher Education 52:470-89 (Sept./Oct. 1981); George F. Keller, Academic Strategy: The Management Revolution in American Higher Education (Baltimore: Johns Hopkins University Press, 1983); Richard W. Jonsen, "The Environmental Context for Postsecondary Education," in Environmental Scanning for Strategic Leadership, ed. P. M. Callan (San Francisco: JosseyBass, 1986), p.5-19; George A. Steiner, Strategic Planning: What Every Manager Must Know (New York: Free Press, 1979).

3. Charles R. McClure, "The Planning Process: Strategies for Action," College \& Research Libraries 39:456-66 (Nov. 1978); Charles R. McClure, "Planning for Library Services: Lessons and Opportunities," Journal of Library Administration 2, nos. 2,3,4:7-28 (1981); James S. Healey, "Staff Participation in Planning: Developing Effective Group Process," Journal of Library Administration 2, nos. 2,3,4:217-33 (1981); R. T. Lenz and others, "Tackling the Human Problems in Planning," Long Range Planning 14:72-77 (Apr. 1981).

4. Elizabeth J. Wood, "Strategic Planning and the Marketing Process: Library Applications," Journal of Academic Librarianship 9:15-20 (Mar. 1983).

5. Donald E. Riggs, Strategic Planning for Library Managers (Phoenix, Ariz.: Oryx, 1984), p.x.

6. Barbara J. Moran, "Strategic Planning in Higher Education," CERL News 46:290 June 1985).

7. Mark Meredith, Robert G. Cope, and Oscar T. Lenning, Differentiating Bonafide Strategic Planning from Other Planning (A study paper, May 1987), 1.

8. Peter F. Drucker, Innovation and Entrepreneurship (New York: Harper, 1985).

9. Robert H. Hayes, "Strategic Planning-Forward in Reverse?" Harvard Business Review, 63 (Nov./Dec. 1985), p.118.

10. Robert C. Shirley, "Strategic Planning: An Overview," Successful Strategic Planning: Case Studies, New Directions for Higher Education, no. 64 (San Francisco: Jossey-Bass, 1988).

11. Ida Vincent, "Strategic Planning and Libraries: Does the Model Fit?" Journal of Library Administration 9, no. 3:45 (1988).

12. Donald E. Riggs, "Entrepreneurial Spirit in Strategic Planning," Journal of Library Administration 8:51 (Spring 1987).

13. Donald E. Riggs, "Networking and Institutional Planning," Journal of Library Administration 8:59-67 (Fall/Winter 1987).

14. Rick B. Forsman, "Incorporating Organizational Values into the Strategic Planning Process," Journal of Academic Librarianship 16:152 (July 1990).

15. James F. Wood II, ed., "Strategic Planning in Higher Education, Implementing New Roles for the Academic Library," Journal of Library Administration 13, nos. 3,4 (1990).

16. Bonnie Gratch and Elizabeth Wood, "Strategic Planning: Implementation and FirstYear Appraisal," Journal of Academic Librarianship 17:10-15 (Mar. 1991).

17. Brice G. Hobrock, "Creating Your Library's Future through Effective Strategic Planning," Journal of Library Administration 14, no. 2 (1991), p.53.

18. Helen Howard, "Innovation in University Organization: The Communication Model," Journal of Academic Librarianship 6:77 (May 1980).

19. A. Bartlett Giamatti, A Free and Ordered Space: The Real World of the University (New York: Norton, 1988), p.35. 
20. Ibid, p.36.

21. Michael D. Cohen and James G. March, Leadership and Ambiguity: The American College President (New York: McGraw-Hill, 1974), p.3.

22. Keller, Academic Strategy, p.5.

23. Library Issues, 11, no. 4 (Mar. 1991) is devoted to this topic and summarizes a report done by Larry Hardesty and David Kaser, "What Do Academic Administrators Think about the College Library?" Council on Library Resources Grant 8018-A (Apr. 1990).

24. Healey, "Staff Participation," p.217.

25. William J. Pfeiffer and others, Understanding Applied Strategic Planning: A Manager's Guide (San Diego, Calif.: University Associates, 1985), p.49-50.

26. Robert H. Waterman, Jr., "The Seven Elements of Strategic Fit," Journal of Business Strategy 2:69-73 (Winter 1982).

\section{APPENDIX A}

\section{A SUMMARY OF THE 7S FRAMEWORK}

\section{Strategy.}

A coherent set of actions aimed at gaining a sustainable advantage over competition, improving position vis-a-vis customers, or allocating resources.

\section{Structure.}

The organization chart and accompanying baggage that show who reports to whom and how tasks are both divided up and integrated.

\section{Systems.}

The processes and flows that show how an organization gets things done from day to day (information systems, capital budgeting systems, manufacturing processes, quality control systems, and performance measurement systems all would be good examples).

\section{Style.}

Tangible evidence of what management considers important by the way it collectively spends time and attention and uses symbolic behavior. It is not what management says is important; it is the way management behaves.

\section{Staff.}

The people in an organization. Here it is very useful to think not about individual personalities but about corporate demographics.

\section{Shared values (or superordinate goals).}

The values that go beyond, but might well include, simple goal statements in determining corporate destiny. To fit that concept, these values must be shared by most people in an organization.

\section{Skills.}

Aderivative of the rest. Skills are those capabilities that are possessed by an organization as a whole as opposed to the people in it. (The concept of corporate skill as something different from the summation of the people in it seems difficult for many to grasp; however, some organizations that hire only the best and brightest cannot get seemingly simple things done while others perform extraordinary feats with ordinary people.) 


\section{UNLOCK THE "BILLION-DOLIAR SECRET" OF GRANT}

\section{FUNDING FOR YOU AND YOUR PATRONS ...}

\section{Annual Register of GRANT SUPPORT 1993}

26th Edition

\begin{tabular}{|c|}
\hline New Edition! \\
Now published by \\
R.R. Bowker
\end{tabular}

"Comprehensive in scope and number of entries. Well-indexed and easy to use. One of the first resources I'd recommend to individuals seeking information on sources of funding."

- Marcia L. Zuzolo Assistant Director of Sponsored Research Studies Indiana University

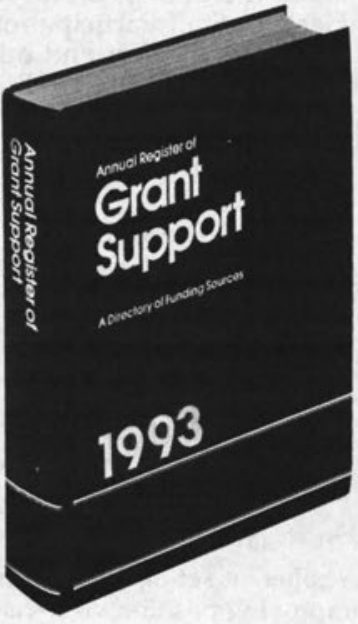

ow can your patrons qualify for grant support? What are the requisites and procedures of some 3,000 funding entities - including unique and nontraditional sources? The Annual Register of Grant Support 1993, now published by R.R. Bowker, has the answers!

Give your patrons access to the billions of funding dollars available from private foundations, corporations, individuals, charitable organizations, and agencies.

The only resource on the subject you'll need in your library, the Annual Register of Grant Support details the application process from the first steps in research to the completion of an effective proposal. Order your copy today!

Annual Register of Grant Support 1993

September $1992 \bullet 0-8352-3293-\mathrm{X} \bullet 1,280 \mathrm{pp} . \bullet \$ 165.00$

Available on Standing Order. Available through your local wholesaler or distributor.
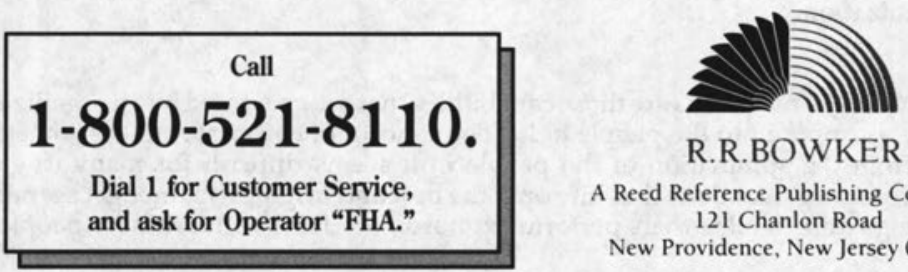

A Reed Reference Publishing Company 121 Chanlon Road

New Providence, New Jersey 07974 